\title{
A retrospective evaluation of the intrauterine device in a patient population in Buenos Aires, Argentina
}

\author{
Sherani R Jagroep, ${ }^{1}$ Margaret S Pichardo, ${ }^{2}$ Lia Arribas, ${ }^{3}$ \\ Graciela Heredia, ${ }^{4}$ Elina Coccio, ${ }^{5}$ Tia M Palermo ${ }^{6}$
}

For numbered affiliations see end of article.

\section{Correspondence to Miss Sherani R Jagroep, Physicians for Reproductive Health, 55 W. 39th Street, Suite 1001, New York, NY 10018, USA; sherani.jagroep@gmail.com}

Received 19 November 2014 Revised 20 July 2015 Accepted 3 September 2015 Published Online First 29 September 2015

\begin{abstract}
Background The intrauterine device (IUD) is a long-acting reversible contraceptive method that is safe for a wide range of women, including adolescents and nulliparous women. Globally, it is often underutilised due to misperceptions among patients. Examination of characteristics associated with IUD discontinuation including adverse effects and IUD expulsion can inform provider practices to improve contraception success and patient satisfaction with this method. We studied IUD performance at a public family planning clinic in Buenos Aires, Argentina, serving a predominantly immigrant, low-income population.
\end{abstract}

Methods We conducted a retrospective evaluation of 1047 IUD insertions between 2002 and 2007 with 5 years of follow-up data. We performed bivariate and survival analysis to examine characteristics associated with IUD discontinuation: adverse outcomes including pain, bleeding, and IUD expulsion, and time to removal.

Findings Of 1047 patients, only 188 (18\%) had their IUD removed within 5 years. The main causes of IUD discontinuation were involuntary (38\%) reasons such as an IUD expulsion and personal choice (34\%) such as desiring pregnancy.

Conclusions Findings suggest overall good long-term performance with IUD insertion, with minimal complaints or adverse outcomes. These findings may help to support providers serving similar populations in promoting this method.

\section{BACKGROUND}

There are approximately 222 million women with an unmet need for contraception in developing countries worldwide and these women account for approximately $82 \%$ of all unintended pregnancies. ${ }^{1-4}$ Access to effective

\section{Key message points}

- The intrauterine device (IUD) is highly effective and well-tolerated by women; they expressed minimal or no complaints of adverse effects.

- Primary reasons for IUD discontinuation within the first 5 years of insertion were a desire to become pregnant or the device was involuntarily expelled.

modern contraception not only reduces unintended pregnancies but may also prevent pregnancy related morbidity and mortality. ${ }^{5-7}$

Benefits of the intrauterine device (IUD) include its efficacy, long-term use, minimal to no interference during coitus, cost-effectiveness, and no recognised systemic effects. ${ }^{8} 9$ In South America, estimates suggest that approximately $7 \%$ of modern contraceptive users are currently using an IUD, compared to $28 \%$ of women globally. ${ }^{1}$

In the middle-income nation of Argentina, the contraceptive prevalence among women of reproductive age (15-49 years) who are married or in a union increased from $53.4 \%$ to $70.4 \%$ between 1990 and 2010. ${ }^{10} 11$ An estimated $10.8 \%$ of contraceptive users in Argentina currently use an IUD as their form of contraception, ${ }^{12}$ which is above average for South America, but well below the global average. ${ }^{1}$

Long-term performance of the IUD remains understudied in Argentina. A better understanding of the IUD's performance and patient satisfaction with its use, based on findings from a clinic that frequently provides the IUD, may increase clinicians' comfort in 
recommending this method to their patients. Studies examining rates of IUD use in the USA have found that low rates of usage may be attributed to limited knowledge of the IUD's mechanism of action, its efficacy, side effects, and misperceived risks associated with its use among both women and clinicians. ${ }^{13-16}$

In the current study, we performed a 5-year retrospective evaluation of IUD insertions between 2002 and 2007 at a public hospital in Buenos Aires, Argentina. We aim to describe the IUD's performance as well as patient experiences. We assessed reasons for discontinuation, time to removal and negative IUD-related outcomes.

To provide context for our study, Argentina's healthcare system is divided into three systems: the public sector, the health insurance sector obtained through employment, and the private sector. The public sector consists of public hospitals and health centres that provide medical care to individuals without insurance or the ability to pay for their healthcare costs. ${ }^{17}$ This study was conducted at a public hospital where patients can obtain family planning services, including the IUD, free of charge.

\section{METHODS}

\section{Sample}

We included a sample of 1161 women who had an IUD inserted at a family planning clinic of a public hospital in Buenos Aires. Patients were included in our study if they were aged 18 years or older (younger women were seen at a separate adolescent clinic) and had an IUD inserted at the same clinic between 2002 and 2007.

Data were collected in Spanish using statistical software SPSS V.21 (SPSS, Inc, Chicago, Illinois, USA) and translated from Spanish to English by our study team. The institutional review board of Stony Brook University and the Bioethics Committee of Hospital Bernardino Rivadavia approved the protocol and procedures of this study.

\section{Measures}

Patient characteristics collected from medical records included: nationality, education level, employment, marital status, age at IUD insertion, and all previous contraceptive methods used (see Appendix). We also retrieved reproductive history, including number of pregnancies, births, caesarean sections, and miscarriages. IUD insertion data included date of insertion and type of IUD (Cu-T380A, Cu-T375, LNG-IUS). Information collected during follow-up visits included: date of visit, condition of IUD, outcomes, and symptoms (see Appendix). Lastly, if an IUD was indicated as being removed during a follow-up visit, additional information on date of removal, reason and ease of removal were also collected (see Appendix).

We also created a binary variable to indicate if a woman was receiving an IUD for the first time or if they were previous IUD recipients; this information was identified by contraceptive history reported on medical records.

Data for each IUD insertion were collected for up to 5 years from initial insertion date or until the IUD was removed or replaced. By subtracting date of insertion from date of removal, time to IUD removal was calculated in days for the survival analysis described in more detail below.

\section{Statistical analysis}

Frequency and percent distributions were obtained on patient characteristics, IUD-related symptoms, and reasons for discontinuation. Patient characteristics were examined by using $\chi^{2}$ tests to examine significant differences among women who were receiving their first IUD and those who have had one previously. Percent distributions were also obtained for adverse IUD-related outcomes (see Appendix).

We examined reasons for IUD removal, classified as an involuntary reason, a complication, a personal preference, and none specified (see Appendix). These reasons were assessed in association with time to removal ( 2 weeks, 1 month, 3 months, 1 year, 3 years, and 5 years).

Kaplan-Meier survival curves examining time to removal were plotted separately for an involuntary reason, a complication, and a personal preference. Differences in these survival curves were assessed with a log-rank test. All analyses were conducted using statistical analysis software Stata V.12 (StataCorp, LP, College Station, Texas, USA).

\section{RESULTS}

A total of 1161 patients had an IUD inserted within the study timeframe. Our final analytic sample consisted of 1047 unique women who received the $\mathrm{Cu}-\mathrm{T} 380 \mathrm{~A}$ or $\mathrm{Cu}-\mathrm{T} 375$ IUD. We excluded three $(<1 \%)$ women with the LNG-IUS; 59 (5.1\%) women who were immediately lost to follow-up after their IUD insertion; and 52 (4.5\%) women who were missing data for patient characteristics and outcomes of interest.

Age at insertion ranged from 20 to 53 years (mean age 32 years). About one-fifth (21\%) of patients were nulliparous and $26 \%$ had three or more children (mean parity 2). Most women were Catholic (89\%) and the majority were Argentinian (51\%). The majority of women $(86 \%)$ were domestically employed as a housewife or maid; only 3\% were unemployed and $11 \%$ had other forms of employment. Of the 1047 women who had an IUD inserted during our study time frame, about one-third (350,33\%) were previous IUD recipients; of this sample, 99 (28\%) were having an IUD replaced (Table 1).

Adverse outcomes included: 20 (1.9\%) expulsions; 79 (7.5\%) partial expulsions; $286(27.3 \%)$ complaints of irregular bleeding; 17 (1.7\%) cases of pelvic 
Table 1 Sociodemographic characteristics

\begin{tabular}{|c|c|c|c|c|}
\hline & $\begin{array}{l}\text { Total }(n=1047) \\
n(\%)\end{array}$ & $\begin{array}{l}\text { First time IUD user }(n=697) \\
n(\%)\end{array}$ & $\begin{array}{l}\text { Previous IUD user }(n=350) \\
n(\%)\end{array}$ & $\begin{array}{l}\chi^{2} \text { test of significance } t \\
p \text { Value }\end{array}$ \\
\hline \multicolumn{5}{|l|}{ Age (years) } \\
\hline $21-25$ & $211(20.2)$ & $195(28.0)$ & $16(4.6)$ & $0.000^{* * *}$ \\
\hline $26-30$ & $267(25.5)$ & $209(30.0)$ & $58(16.6)$ & $0.000 * * *$ \\
\hline $31-35$ & $245(23.4)$ & $157(22.5)$ & $88(25.1)$ & 0.345 \\
\hline $36-40$ & $166(15.9)$ & $81(11.6)$ & $85(24.3)$ & $0.000 * * *$ \\
\hline $41-45$ & $116(11.1)$ & $47 \quad(6.7)$ & 69 (19.7) & $0.000 * * *$ \\
\hline$>45$ & $42(4.0)$ & $8(1.2)$ & $34 \quad(9.7)$ & $0.000^{* * *}$ \\
\hline \multicolumn{5}{|l|}{ Nationality } \\
\hline Argentinian & $538(51.4)$ & $330(47.4)$ & $208(59.4)$ & 0.001 ** \\
\hline Other nationalities & $509(48.6)$ & $367(52.7)$ & $142(40.6)$ & $0.001 * *$ \\
\hline \multicolumn{5}{|l|}{ Religion } \\
\hline Catholic & $931(88.9)$ & $624(89.5)$ & $307(87.7)$ & 0.378 \\
\hline Evangelical & $47 \quad(4.5)$ & 32 (4.6) & $15(4.3)$ & 0.822 \\
\hline No religion & $45 \quad(4.5)$ & $24 \quad(3.4)$ & $21 \quad(6.0)$ & 0.054 \\
\hline Other & $24 \quad(2.3)$ & $17 \quad(2.5)$ & $7 \quad(2.0)$ & 0.654 \\
\hline \multicolumn{5}{|l|}{ Education } \\
\hline Primary & $448(42.8)$ & $304(43.6)$ & $144(41.1)$ & 0.446 \\
\hline Secondary & $501(47.9)$ & $336(48.2)$ & $165(47.1)$ & 0.745 \\
\hline More than secondary & $98 \quad(9.4)$ & $57 \quad(8.2)$ & $41(11.7)$ & 0.064 \\
\hline \multicolumn{5}{|l|}{ Employed } \\
\hline Employed & $30 \quad(2.9)$ & $15 \quad(2.2)$ & $15(4.3)$ & $0.008^{* *}$ \\
\hline Domestically employed & $114(10.9)$ & $65 \quad(9.3)$ & $49(14.0)$ & $0.008^{* *}$ \\
\hline Unemployed & $903(86.3)$ & $617(88.5)$ & $286(81.7)$ & $0.003^{* *}$ \\
\hline \multicolumn{5}{|l|}{ Marital status } \\
\hline Married & $402(38.4)$ & $224(32.1)$ & $178(50.9)$ & $0.000 * * *$ \\
\hline Single & $366(35.0)$ & $276(39.6)$ & $90(25.7)$ & $0.000 * * *$ \\
\hline Separated/divorced & $37 \quad(3.5)$ & $11(1.6)$ & $26 \quad(7.4)$ & $0.000 * * *$ \\
\hline Widowed & $6(0.6)$ & $3(0.4)$ & $3(0.9)$ & 0.388 \\
\hline In a relationship & $236(22.5)$ & $183(26.3)$ & $53(15.1)$ & $0.000 * * *$ \\
\hline \multicolumn{5}{|l|}{ Parity } \\
\hline Nulliparous & $217(20.7)$ & $160(23.0)$ & $57(16.3)$ & $0.012^{*}$ \\
\hline Parous (1-2 births) & $557(53.2)$ & $374(53.7)$ & $183(52.3)$ & 0.675 \\
\hline Parous ( $>2$ births) & $273(26.1)$ & $163(23.4)$ & $110(31.4)$ & $0.005^{* *}$ \\
\hline
\end{tabular}

${ }^{*} p<0.05,{ }^{* *} p<0.01,{ }^{* * *} p<0.001$.

$+\chi^{2}$ test for significance between first-time and previous IUD recipients at $\alpha=0.05$.

IUD, intrauterine device.

inflammatory disease; $72(6.9 \%)$ cases of sexually transmitted infections; 1 (0.1\%) pregnancy; and 1 $(0.1 \%)$ uterine perforation.

Within the 5-year study time frame 188 women removed their IUD. Reasons for discontinuation were involuntary $(38 \%)$, such as an IUD expulsion, or by choice $(34 \%)$, such as wanting to become pregnant; few $(12 \%)$ removed their IUD due to a complication, such as pelvic pain or pregnancy; and 16\% did not have a reason for IUD removal noted in their charts. Involuntary reasons for IUD removal occurred more frequently earlier. The percentage of removals due to involuntary reasons were: $71 \%$ at 2 weeks; $67 \%$ at 1 month; $71 \%$ at 3 months; and $61 \%$ at 1 year. After the first year, reasons for removal were primarily by choice. At 3 and 5 years, 39\% and 58\% of removals were by choice, respectively (Table 2 ).

Figure 1 shows the Kaplan-Meier survival curves for time to IUD removal due to an involuntary reason, a complication or a choice. IUD discontinuation due to involuntary reasons occurred earlier in the 5-year timeline. Log-rank tests indicated there were differences in survival curves between those who removed their IUD for an involuntary reason, a complication or by choice $(\mathrm{p}<0.001)$.

\section{DISCUSSION}

This study is among the first to our knowledge to examine patient characteristics associated with IUD 
Table 2 Reasons for IUD removal $(n=188)$

\begin{tabular}{|c|c|c|c|c|c|c|c|}
\hline Reasons for IUD removal & Total (\%) & 2 weeks (\%) & 1 month (\%) & 3 months (\%) & 1 year $(\%)$ & 3 years $(\%)$ & 5 years $(\%)$ \\
\hline Involuntary & 38 & 71 & 67 & 71 & 61 & 24 & 10 \\
\hline Complication & 12 & 0 & 17 & 5 & 18 & 17 & 10 \\
\hline Choice & 34 & 6 & 0 & 5 & 21 & 39 & 58 \\
\hline None specified & 16 & 24 & 17 & 19 & 0 & 20 & 22 \\
\hline Total $(n)$ & 188 & 17 & 6 & 21 & 38 & 46 & 60 \\
\hline
\end{tabular}

See Appendix for lists of the specific reasons 'Involuntary', 'Complication' and 'Choice'.

IUD, intrauterine device.

performance in a recent Argentinian patient population; existing studies date before $1990 .^{16}$

Primary reasons for IUD discontinuation were involuntary, mainly due to an expulsion or a partial expulsion (81\%), and by choice, predominantly to become pregnant $(55 \%)$. Few (12\%) discontinued due to a complication such as pelvic pain or bleeding. Current literature validates reasons for IUD discontinuation due to expulsions and personal choice. ${ }^{3} 618$ Our study provides a timeline of IUD removals to elucidate that IUD discontinuations within the first year of insertion were primarily involuntary and removals after 3 years were by choice.
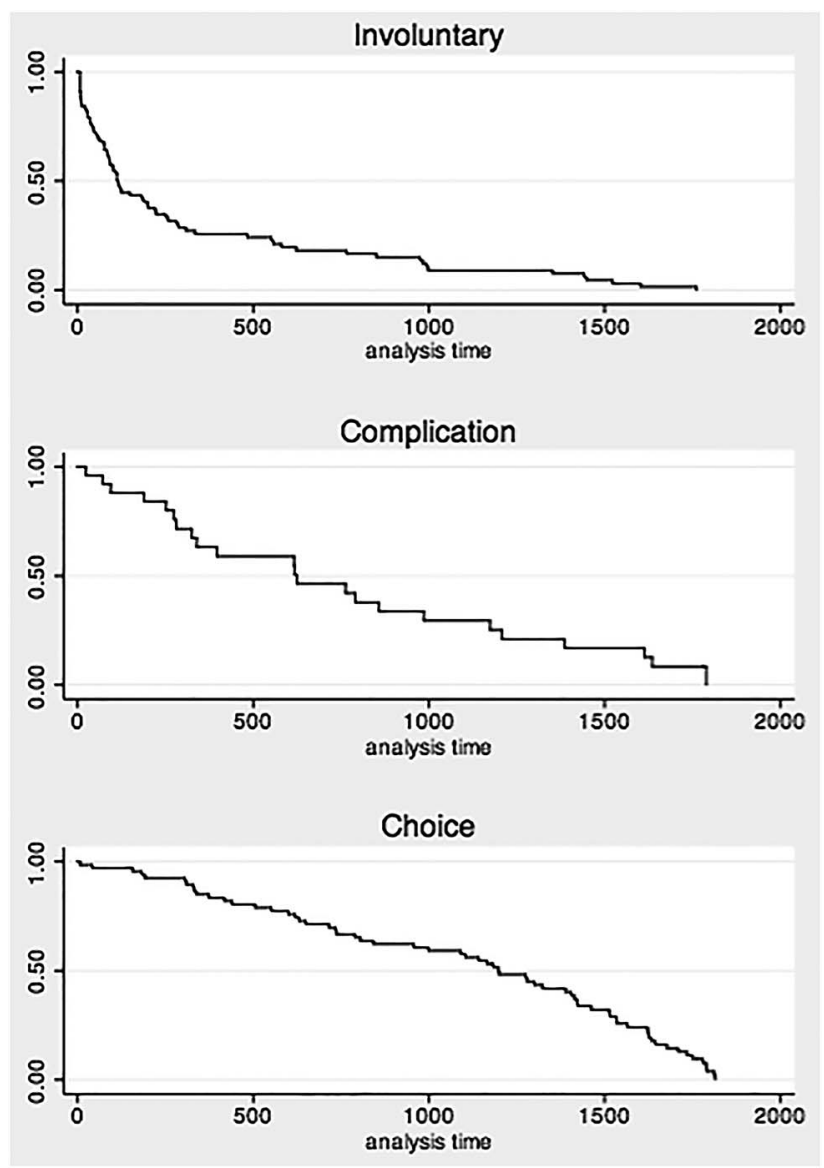

Figure 1 Kaplan-Meier survival curves for reasons for intrauterine device (IUD) removal ( $n=188)$ : 'Involuntary', 'Complication' and 'Choice'. See Appendix for list of reasons. Note: analysis time in days post-insertion day (0).
A similar retrospective study was conducted at a family planning clinic in Brazil on a smaller sample size $(n=118)$; their continuation rate was $45 \%$ compared to $82 \%$ in our study. Major differences include sample size and loss to follow-up ( $21 \%$ vs $5 \%$ in our study). ${ }^{19}$ The low rate of IUD removal 5 years postinsertion, the low incidence of adverse symptoms, and the primarily involuntary reasons for IUD removal indicate that women had an overall positive experience with this method of contraception.

Limitations of this study include the retrospective nature of data collection from patient charts. It is possible that some adverse outcomes were underreported in the patient files or not diagnosed due to limited resources. Lastly, our data came from one family planning clinic in Argentina, therefore generalisability may be limited.

\section{CONCLUSION}

Our study demonstrates overall positive experiences with IUD use in a Buenos Aires patient population, with low rates of discontinuation, minimal adverse effects, and high efficacy. Offering the IUD cost-free to similar populations may also result in high continuation rates and provide low-to-middle income women autonomy in their family planning needs while reducing unintended pregnancies.

\section{Implications for practice and public policy}

These findings may encourage providers who are considering providing the IUD to similar populations, and restore comfort in women who fear adverse outcomes.

\section{Author affiliations}

${ }^{1}$ Education, Research and Training Associate, Physicians for Reproductive Health (work was conducted while at Stony Brook University), New York, NY 10018, USA

${ }^{2}$ Howard University College of Medicine, MS1 (work was conducted while at Stony Brook University), Washington DC, 20001

${ }^{3}$ Obstetrician Gynecologist, Department of Gynecology, Hospital Bernardino Rivadavia, Buenos Aires Ministry of Health, Buenos Aires, Argentina ${ }^{4}$ Obstetrician Gynecologist, Department of Gynecology, Hospital Bernardino Rivadavia, Buenos Aires Ministry of Health, Buenos Aires, Argentina 
${ }^{5}$ Obstetrician Gynecologist, Department of Gynecology, Hospital Bernardino Rivadavia, Buenos Aires Ministry of Health, Buenos Aires, Argentina ${ }^{6}$ Assistant Professor, Program in Public Health, Department of Preventative Medicine, Stony Brook University (State University of New York), Health Sciences Center 3-021, Stony Brook, NY 11790, USA

Competing interests None declared.

Ethics approval The Institutional Review Boards of Stony Brook University and Hospital Bernardino Rivadavia.

Provenance and peer review Not commissioned; externally peer reviewed.

Data sharing statement SRJ, MSP and TMP had full access to the data in a secure shared folder. Unpublished data from our study has not been made available to any other constituents.

\section{REFERENCES}

1 Darroch JE, Singh S. Trends in contraceptive need and use in developing countries in 2003, 2008, and 2012: an analysis of national surveys. Lancet 2013;381:1756-1762.

2 Darroch JE, Sedgh G, Ball H. Contraceptive Technologies: Responding to Women's Needs. New York: Guttmacher Institute, 2011.

3 Hubacher D. Copper intrauterine device use by nulliparous women: review of side effects. Contraception 2007;75 (6, Suppl):S8-S11.

4 Singh S, Darroch JE. Adding it up: Costs and Benefits of Contraceptive Services, Estimates for 2012. New York: Guttmacher Institute, 2012.

5 Hubacher D, Chen P, Park S. Side effects from the copper IUD: do they decrease over time? Contraception 2009;79: 356-362.

6 O’Brien PA, Kulier R, Helmerhorst FM, et al. Coppercontaining, framed intrauterine devices for contraception: a systematic review of randomized controlled trials. Contraception 2008;77:318-327.

7 Rawe K, Dunford A, Stewart J. 2012. Misconception: Why Family Planning Actually Saves Babies' Lives. London. Save the Children, 2012.

8 Mishell DR Jr. Intrauterine contraception: benefits to patients. J Fam Pract 2004;10/2004(Suppl):S9-S14.

9 Dean G, Schwartz EB. Intrauterine contraceptives (IUCs). In: Hatcher Robert A, Trussell James, \& Nelson Anita L, editors. Contraceptive Technology. New York: Ardent Media; 2011:147-91.

10 Pantelides EA, Binstock G, Mario S. The reproductive health of women in Argentina, 2005. Results of the national survey of nutrition and health. 2007.

11 Situación de la población en la Argentina. Buenos Aires, Argentina: Population Fund of the United Nations in Argentina (UNFPA). 2009.

12 Alkema L, Kantorova V, Menozzi C, et al. National, regional, and global rates and trends in contraceptive prevalence and unmet need for family planning between 1990 and 2015: a systematic and comprehensive analysis. Lancet 2013;381:1642-1652.

13 Dehlendorf C, Levy K, Ruskin R, et al. Health care providers' knowledge about contraceptive evidence: a barrier to quality family planning care? Contraception 2009;81: 292-298.
14 Ruben SE, Fletcher J, Stein T, et al. Determinants of intrauterine contraception provision among US family physicians: a national survey of knowledge, attitudes and practice. Contraception 2011;83:472-478.

15 Madden T, Allsworth JE, Hladky KJ, et al. Intrauterine contraception in Saint Louis: a survey of obstetrician and gynecologists' knowledge and attitudes. Contraception 2010;81:112-116.

16 Wellings K, Zhihong Z, Krentel A, et al. Attitudes towards long-acting reversible methods of contraception in general practice in the UK. Contraception 2007;76:208-214.

17 Belló M, Becerril-Montekio V. Sistema de salud de Argentina. Vol 53. Salud Publica de Mexico, 2011.

18 Ferreira JM, Nunes FR, Modesto W, et al. Reasons for Brazilian women to switch from different contraceptives to long-acting reversible contraceptives. Contraception 2014;89:17-21.

19 de Araujo FF, Barbieri M, Guazzelli CA, et al. The T 380A intrauterine device: a retrospective 5 -year evaluation. Contraception 2008;78:474-478.

\section{Appendix}

I. Information collected from patient charts

Nationality Argentinian versus other

Education level Primary, secondary, beyond secondary

Employment Employed, domestically employed, unemployed

Marital status In a relationship, married, single, separated or

Condition of IUD Expelled

Partial expulsion

Partner complains of discomfort

Removed

Replaced

String cut

String discomfort

Outcomes and Anaemia

symptoms Irregular bleeding

Menopause

Pelvic inflammatory disease

Pelvic pain

Pregnancy

Sexually transmitted infection

Uterine perforation

II. Reasons for IUD removal

Involuntary

IUD expelled

IUD partially expelled

IUD replacement

IUD removed accidentally

Non-IUD related procedure

Complication Anaemia

Became pregnant

Irregular bleeding

Partner feels discomfort with string

Pelvic inflammatory disease

Pelvic pain

Uterine perforated

Choice

No sexual relationship

Menopause

Wanted pregnancy

Wanted other birth control method

Wanted oral contraceptives

None specified

IUD, intrauterine device. 